Vietnam Journal of Mechanics, VAST, Vol.42, No. 2 (2020), pp. 123 -132

DOI: https://doi.org/10.15625/0866-7136/14707

\title{
MODE SHAPE CURVATURE OF MULTIPLE CRACKED BEAM AND ITS USE FOR CRACK IDENTIFICATION IN BEAM-LIKE STRUCTURES
}

\author{
Nguyen Tien Khiem ${ }^{1, *}$ \\ ${ }^{1}$ Institute of Mechanics, VAST, Hanoi, Vietnam \\ *E-mail: ntkhiem@imech.vast.vn
}

Received: 18 December 2019 / Published online: 23 April 2020

\begin{abstract}
The problem of using the modal curvature for crack detection is discussed in this paper based on an exact expression of mode shape and its curvature. Using the obtained herein exact expression for the mode shape and its curvature, it is demonstrated that the mode shape curvature is really more sensitive to crack than mode shape itself. Nevertheless, crack-induced change in the approximate curvature calculated from the exact mode shape by the central finite difference technique (Laplacian) is much greater in comparison with both the mode shape and curvature. It is produced by the fact, shown in this study, that miscalculation of the approximate curvature is straightforwardly dependent upon crack magnitude and resolution step of the finite difference approximation. Therefore, it can be confidently recommended to use the approximate curvature for multiple crack detection in beam by properly choosing the approximation mesh. The theoretical development has been illustrated by numerical results.

Keywords: multiple-cracked beams, crack detection, mode shape curvature, Laplacian approximation.
\end{abstract}

\section{INTRODUCTION}

Structural damage identification problem has attached enormous interest of either researchers or engineers for several decades. Among a large number of techniques proposed to solve the problem, vibration-based method has proved to be the most efficient approach [1-4]. This is because a damage occurred in a structure alters straightforwardly the structure's dynamical characteristics that can be measured by the well-developed modal testing technique. Natural frequencies and mode shapes of a structure are the essential characteristics for structural damage detection. The frequencies are early used for the structural damage detection [5] because they can be most easily and accurately measured by the dynamic testing technique. However, as a global feature of a structure, natural frequencies are slightly sensitive to local damages that should be appropriately

(c) 2020 Vietnam Academy of Science and Technology 
detected by using the spatial feature of structures such as the mode shapes [6,7]. Nevertheless, mode shapes are more difficult to be accurately determined, so that change in mode shape due to damage might be confused with measurement noise or modeling erroneousness [8]. To overcome the drawbacks of the frequency-based and mode shape-based methods, numerous procedures have been proposed to use mutually both the modal parameters (frequency and mode shape) and their derivatives such as flexibility, strain energy for the damage detection problem. Most of the developments focused on engaging more refined behavior of spatial characteristics in damaged structures such as mode shape curvature [9-14]. Pandey et al. [15] first revealed that change in mode shape curvature due to damage is greater than that of mode shape itself and stated that the curvature is a good indicator for damage detection in beams. In the study, curvature was calculated from mode shape by using the central finite difference approximation acknowledged as Laplacian operator. Then, Wahab [16] expanded the modal curvature technique and applied for damage detection in a real bridge. Ratcliffe $[17,18]$ improved the curvature-based technique of damage detection by using the so-called gapped smoothing procedure to detect small damage that could not be identified by the proposed curvature technique. Cao and Qiao [19] proposed a modification of the Laplacian scheme in combination with the Gaussian filter to ignore measurement noise, so that much enhanced the curvature-based technique. Chandrashekhar and Ganguli [20] applied the fuzzy logic system that allows the curvature-based technique to detect small damage with noisy measured mode shape. The wavelet transform is a useful tool for revealing small localized change in a signal [21] and was employed for crack detection in beam structures using mode shape [22] and curvature [23]. However, it requires a large amount of input data and is strongly sensitive to noise or miscalculation of input data. Most of the studies mentioned above employed the finite element method for modeling damaged structures that usually proposes rather distributed damage than the local one such as crack. The error in finite element modeling damaged structures may affect results of the damage identification, especially, in detecting local damage like crack. So, the present paper deals with discussion on the use of the curvature-based technique for multiple crack detection based on an explicit expression established for exact mode shape and its curvature of multiple cracked beams [24]. The established expression allows one to investigate sensitivity of exact mode shape and its curvature to crack and obtain miscalculation of the Laplacian operator applied for multiple cracked beam. There is demonstrated that the miscalculation increases sensitivity of the approximate curvature compared to the exact one and it is straightforwardly dependent not only on crack location and depth but also on the step of resolution mesh.

\section{AN EXPRESSION FOR EXACT CURVATURE OF MULTIPLE CRACKED BEAM}

Let's consider an Euler-Bernoulli beam with elasticity module $E$, mass density $\rho$, length $L$, cross section area $F$ and moment of inertia $I$. Assume that the beam is cracked at positions $e_{j}, j=1, \ldots, n$ and the equivalent spring model of crack is adopted with the crack magnitude $\gamma_{j}$ calculated from the crack depth $a_{j}$ as [25] 


$$
\begin{aligned}
\gamma_{j}= & \frac{E I}{L K_{j}}=(5.346 \mathrm{H} / \mathrm{L}) I\left(\delta_{j}\right), \\
I(\delta)= & 1.8624 \delta^{2}-3.95 \delta^{3}+16.375 \delta^{4}-37.226 \delta^{5}+76.81 \delta^{6} \\
& -126.9 \delta^{7}+172 \delta^{8}-143.97 \delta^{9}+66.56 \delta^{10}, \quad \delta_{j}=a_{j} / h,
\end{aligned}
$$

where $h$ is the beam thickness. As well known that modal parameters of the beam such as natural frequency and mode shape satisfy the equation

$$
\phi^{(I V)}(x)-\lambda^{4} \phi(x)=0, \quad x \in(0,1), \quad \lambda^{4}=L^{4} \rho F \omega^{2} / E I,
$$

and compatibility conditions at the crack positions

$$
\begin{gathered}
\phi\left(e_{j}+0\right)=\phi\left(e_{j}-0\right), \quad \phi^{\prime \prime}\left(e_{j}+0\right)=\phi^{\prime \prime}\left(e_{j}-0\right), \quad \phi^{\prime \prime \prime}\left(e_{j}+0\right)=\phi^{\prime \prime \prime}\left(e_{j}-0\right), \\
\phi^{\prime}\left(e_{j}+0\right)=\phi^{\prime}\left(e_{j}-0\right)+\gamma_{j} \phi_{j}^{\prime \prime}\left(e_{j}-0\right) .
\end{gathered}
$$

The conventional boundary conditions for solution of Eq. (2) can be expressed in general form

$$
\phi^{\left(p_{0}\right)}(0)=\phi^{\left(q_{0}\right)}(0)=\phi^{\left(p_{1}\right)}(1)=\phi^{\left(q_{1}\right)}(1)=0 .
$$

In the paper [24], it was shown that solution of Eqs. (2), (3) can be represented as

$$
\phi(x, \lambda)=C L_{1}(x, \lambda)+D L_{2}(x, \lambda),
$$

where

$$
\begin{gathered}
L_{1}(x, \lambda)=L_{01}(x, \lambda)+\sum_{j=1}^{n} \mu_{1 j} K\left(x-e_{j}\right), \quad L_{2}(x, \lambda)=L_{20}(x, \lambda)+\sum_{j=1}^{n} \mu_{2 j} K\left(x-e_{j}\right), \\
K^{(r)}(x)=\left\{\begin{array}{ll}
S^{(r)}(x), & \text { for } x \geq 0 \\
0, & \text { for } x \leq 0
\end{array} \quad r=0,1,2,3\right. \\
\quad S(x)=(\sinh \lambda x+\sin \lambda x) / 2 \lambda, \\
\mu_{k j}=\gamma_{j}\left[L_{k 0}^{\prime \prime}\left(e_{j}\right)+\sum_{i=1}^{j-1} \mu_{k i} S^{\prime \prime}\left(e_{j}-e_{i}\right)\right], \quad k=1,2, \quad j=1, \ldots, n
\end{gathered}
$$

and functions $L_{10}(x), L_{20}(x)$ are two independent particular solutions of Eq. (2) continuous inside the beam and satisfying boundary conditions $L_{10}^{\left(p_{0}, q_{0}\right)}(0)=L_{20}^{\left(p_{0}, q_{0}\right)}(0)=0$. Obviously, the solution (5) satisfies also first two conditions at $x=0$ in (4), so that the remained two conditions (4) at $x=1$ for the solution become

$$
C L_{1}^{\left(p_{1}\right)}(1, \lambda)+D L_{2}^{\left(p_{1}\right)}(1, \lambda)=0, \quad C L_{1}^{\left(q_{1}\right)}(1, \lambda)+D L_{2}^{\left(q_{1}\right)}(1, \lambda)=0 .
$$

The later equations have non-trivial constants $C, D$ if

$$
L_{1}^{\left(p_{1}\right)}(1, \lambda) L_{2}^{\left(q_{1}\right)}(1, \lambda)-L_{1}^{\left(q_{1}\right)}(1, \lambda) L_{2}^{\left(p_{1}\right)}(1, \lambda)=0 .
$$

Substitution of expressions (6) into Eq. (11) leads to

$$
F_{0}(\lambda)+\sum_{j=1}^{n} \mu_{1 j} F_{1 j}\left(\lambda, e_{j}\right)+\sum_{j=1}^{n} \mu_{2 j} F_{2 j}\left(\lambda, e_{j}\right)+\sum_{j, k=1}^{n} \mu_{1 j} \mu_{2 k} S_{p q}\left(\lambda, e_{j}, e_{k}\right)=0
$$


where

$$
\begin{aligned}
F_{1 j} & =L_{20}^{\left(q_{1}\right)}(1) S^{\left(p_{1}\right)}\left(1-e_{j}\right)-L_{20}^{\left(p_{1}\right)}(1) S^{\left(q_{1}\right)}\left(1-e_{j}\right), \\
F_{2 j} & =L_{10}^{\left(p_{1}\right)}(1) S^{\left(q_{1}\right)}\left(1-e_{j}\right)-L_{10}^{\left(q_{1}\right)}(1) S^{\left(p_{1}\right)}\left(1-e_{j}\right), \\
F_{0}(\lambda) & =L_{10}^{\left(p_{1}\right)}(1) L_{20}^{\left(q_{1}\right)}(1)-L_{10}^{\left(q_{1}\right)}(1) L_{20}^{\left(p_{1}\right)}(1), \\
S_{p q} & =S^{\left(p_{1}\right)}\left(1-e_{j}\right) S^{\left(q_{1}\right)}\left(1-e_{k}\right)-S^{\left(q_{1}\right)}\left(1-e_{j}\right) S^{\left(p_{1}\right)}\left(1-e_{k}\right) .
\end{aligned}
$$

Eq. (12) gives an explicit form of the so-called characteristic equation for multiple cracked beam that could be solved straightforwardly with regard to $\lambda$ under given crack positions and magnitudes $e_{j}, \gamma_{j}, j=1, \ldots, n$. Indeed, the recurrent relationships (9) for the parameters $\mu_{1 j}, \mu_{2 j}, j=1, \ldots, n$ can be rewritten as

$$
[\mathbf{A}]\left\{\boldsymbol{\mu}_{k}\right\}=\left\{\mathbf{b}_{k}\right\},
$$

where the following matrix and vectors are used

$$
\begin{gathered}
{[\mathbf{A}]=\left[a_{j i}: a_{j j}=1, a_{j i}=-\gamma_{j} S^{\prime \prime}\left(e_{j}-e_{i}\right), i \prec j, a_{j i}=0, i \succ j, j=1, \ldots, n\right],} \\
\left\{\mathbf{b}_{k}\right\}=\left\{\gamma_{1} L_{k 0}^{\prime \prime}\left(e_{1}\right), \ldots, \gamma_{n} L_{k 0}^{\prime \prime}\left(e_{n}\right)\right\}^{T}, \quad\left\{\boldsymbol{\mu}_{k}\right\}=\left\{\mu_{k 1}, \ldots, \mu_{k n}\right\}^{T} .
\end{gathered}
$$

Since $\operatorname{det}[\mathbf{A}]=1$ it is easily to obtain $\left\{\boldsymbol{\mu}_{k}\right\}=[\mathbf{A}]^{-1}\left\{\mathbf{b}_{k}\right\}, k=1,2$ that allow completely calculating the parameters $\mu_{1 j}, \mu_{2 j}, j=1, \ldots, n$ with given the crack parameters. Solution of Eq. (12) in combination with Eq. (14) gives rise the so-called eigenvalues $\lambda_{k}, k=1,2,3, \ldots$ of the multiple cracked beam that are simply related to natural frequencies of the beam by

$$
\omega_{k}=\left(\lambda_{k} / L\right)^{2} \sqrt{E I / \rho F}, \quad k=1,2,3, \ldots
$$

Every eigenvalue or natural frequency associates with a mode shape determined as

$$
\Phi_{k}(x)=\phi\left(x, \lambda_{k}\right)=C_{k}\left[L_{2}^{\left(p_{1}, q_{1}\right)}\left(1, \lambda_{k}\right) L_{1}\left(x, \lambda_{k}\right)-L_{1}^{\left(p_{1}, q_{1}\right)}\left(1, \lambda_{k}\right) L_{2}\left(x, \lambda_{k}\right)\right] .
$$

where $C_{k}$ is arbitrary constant that can be calculated from a chosen normalization condition, for example,

$$
C_{k}=\left[\max \left\{L_{2}^{\left(p_{1}, q_{1}\right)}\left(1, \lambda_{k}\right) L_{1}\left(x, \lambda_{k}\right)-L_{1}^{\left(p_{1}, q_{1}\right)}\left(1, \lambda_{k}\right) L_{2}\left(x, \lambda_{k}\right), x \in(0,1)\right\}\right]^{-1}
$$

Hence, a close form solution for exact curvature is easily calculated as

$$
\Phi_{k}^{\prime \prime}(x)=\phi^{\prime \prime}\left(x, \lambda_{k}\right)=C_{k}\left[L_{2}^{\left(p_{1}, q_{1}\right)}\left(1, \lambda_{k}\right) L_{1}^{\prime \prime}\left(x, \lambda_{k}\right)-L_{1}^{\left(p_{1}, q_{1}\right)}\left(1, \lambda_{k}\right) L_{2}^{\prime \prime}\left(x, \lambda_{k}\right)\right] .
$$

The above modal parameters have been obtained for general boundary conditions (4) represented through the functions $L_{10}(x), L_{20}(x)$ that can be easily found for the conventional boundary conditions as following:

(1) Simply supported beam: $L_{10}(x)=\sinh \lambda x, L_{20}(x)=\sin \lambda x$;

(2) Clamped end beam: $L_{10}(x)=\cosh \lambda x-\cos \lambda x ; L_{20}(x)=\sinh \lambda x-\sin \lambda x$;

(3) Free ends beam: $L_{10}(x)=\cosh \lambda x+\cos \lambda x ; L_{20}(x)=(\sinh \lambda x+\sin \lambda x)$. 


\section{SENSITIVITY OF EXACT MODE SHAPE CURVATURE TO CRACK}

The expressions (16) and (18) are used herein to examine deviation of mode shape and modal curvature caused by multiple cracks in beam. Namely, the deviations are calculated as

$$
\Delta \Phi_{k}(x)=\phi\left(x, \lambda_{k}\right)-\phi_{0}\left(x, \lambda_{k}^{0}\right), \quad \Delta \Phi_{k}^{\prime \prime}(x)=\phi^{\prime \prime}\left(x, \lambda_{k}\right)-\phi_{0}^{\prime \prime}\left(x, \lambda_{k}^{0}\right),
$$

where $\lambda_{k}^{0}$ is $k$-th eigenvalue of uncracked beam determined as solution of the equation $F_{0}\left(\lambda_{k}^{0}\right)=0$ (see Eq. (12)), $\phi_{0}\left(x, \lambda_{k}^{0}\right), \phi_{0}^{\prime \prime}\left(x, \lambda_{k}^{0}\right)$ are mode shape and curvature of intact beam determined as

$$
\begin{aligned}
& \phi_{0}\left(x, \lambda_{k}^{0}\right)=C_{k}^{0}\left[L_{20}^{\left(p_{1}, q_{1}\right)}\left(1, \lambda_{k}^{0}\right) L_{10}\left(x, \lambda_{k}^{0}\right)-L_{10}^{\left(p_{1}, q_{1}\right)}\left(1, \lambda_{k}^{0}\right) L_{20}\left(x, \lambda_{k}^{0}\right)\right], \\
& \phi_{0}^{\prime \prime}\left(x, \lambda_{k}^{0}\right)=C_{k}^{0}\left[L_{20}^{\left(p_{1}, q_{1}\right)}\left(1, \lambda_{k}^{0}\right) L_{10}^{\prime \prime}\left(x, \lambda_{k}^{0}\right)-L_{10}^{\left(p_{1}, q_{1}\right)}\left(1, \lambda_{k}^{0}\right) L_{20}^{\prime \prime}\left(x, \lambda_{k}^{0}\right)\right] .
\end{aligned}
$$

The deviations (19) calculated for first three modes of a cantilever beam with 9 cracks (from 0.1 to 0.9 ) along the normalized beam length (horizontal axis) are shown

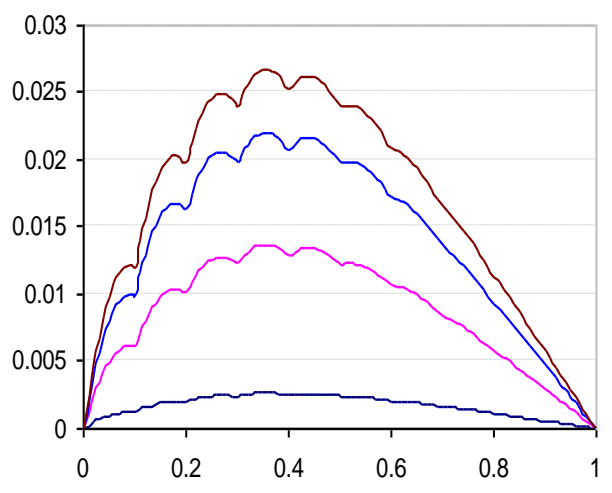

(a) First mode

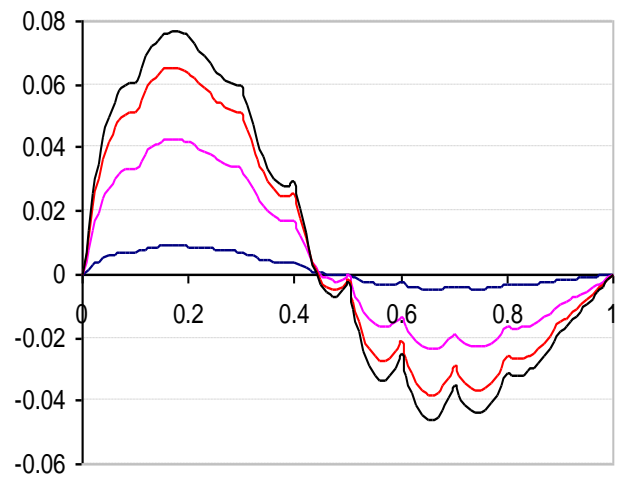

(b) Second mode

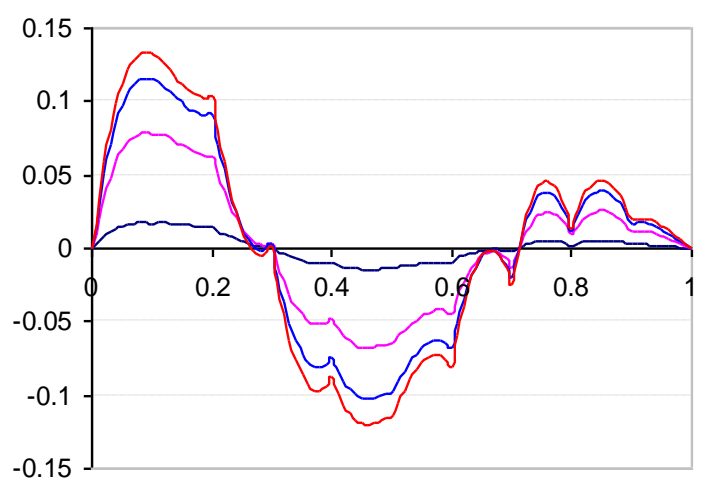

(c) Third mode

Fig. 1. Deviation of three mode shapes due to 9 cracks at $0.1-0.9$ of depths $10 \%, 30 \%, 50 \%, 60 \%$ 
in Figs. 1 and 2 for mode shapes and curvatures respectively. Every box in the Figures demonstrates four curves corresponding to various depth of the cracks from $10 \%$ to $60 \%$ beam thickness that show monotony increasing of the deviation magnitude with the crack depth.

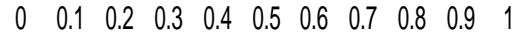

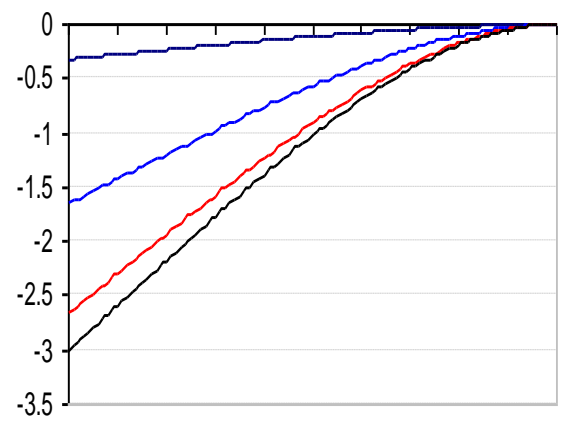

(a) First mode

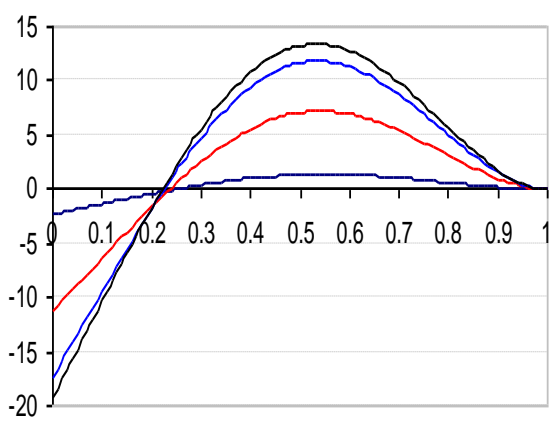

(b) Second mode

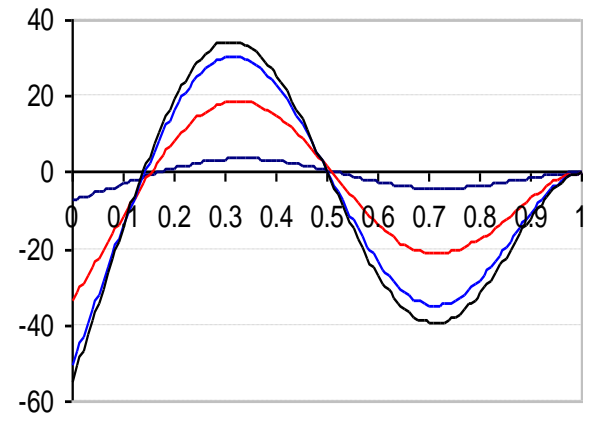

(c) Third mode

Fig. 2. Deviation of exact curvature of three modes due to 9 cracks at $0.1-0.9$ with depth $10 \%, 30 \%, 50 \%, 60 \%$

Note that variation of mode shape due to cracks is visibly observed at the crack positions (see Fig. 1), but magnitude of the variation is very small (within 10\%). So that cracks would be difficult to detect by mode shape measured with error of $10 \%$. Deviation of exact curvature caused by cracks is significantly magnified (see Fig. 2) in comparison with mode shape variation. Nevertheless, the change in modal curvature is rather distributed than localized at the cracks positions so that cracks are also not easily localized from measurement of curvature even if base-line data are available. This encourages us to find another more efficient indicator for the crack detection, one of that is considered in subsequent section. 


\section{SENSITIVITY OF LAPLACIAN APPROXIMATE CURVATURE DUE TO CRACK}

Assume that mode shape and curvature of a beam have been measured at the mesh $\left(x_{0}, x_{1}, \ldots, x_{n+1}\right)$ with resolution $h$ and $x_{0}=0, x_{n+1}=1$, i.e. there are given two sets of data: $\phi\left(x_{j}\right), \phi^{\prime \prime}\left(x_{j}\right), j=0, \ldots, n+1$. Let's consider three subsequent points $\left(x_{j-1}, x_{j}, x_{j+1}\right)$ of the mesh and suppose that each of the segments $\left(x_{j-1}, x_{j}\right),\left(x_{j}, x_{j+1}\right)$ may contains only one crack at position $e_{j-1} \in\left(x_{j-1}, x_{j}\right), e_{j} \in\left(x_{j}, x_{j+1}\right)$, respectively.

Taylor's expansion of the function $\phi(x)$ at the points $e_{j-1}, e_{j}$ yields

$$
\begin{aligned}
\phi\left(x_{j+1}-0\right) & =\phi\left(e_{j}+0\right)+\phi^{\prime}\left(e_{j}+0\right)\left(x_{j+1}-e_{j}\right)+(1 / 2) \phi^{\prime \prime}\left(e_{j}+0\right)\left(x_{j+1}-e_{j}\right)^{2}+\ldots, \\
\phi\left(x_{j}+0\right) & =\phi\left(e_{j}-0\right)+\phi^{\prime}\left(e_{j}-0\right)\left(x_{j}-e_{j}\right)+(1 / 2) \phi^{\prime \prime}\left(e_{j}-0\right)\left(x_{j}-e_{j}\right)^{2}+\ldots, \\
\phi\left(x_{j}-0\right) & =\phi\left(e_{j-1}+0\right)+\phi^{\prime}\left(e_{j-1}+0\right)\left(x_{j}-e_{j-1}\right)+(1 / 2) \phi^{\prime \prime}\left(e_{j-1}+0\right)\left(x_{j}-e_{j-1}\right)^{2}+\ldots, \\
\phi\left(x_{j-1}+0\right) & =\phi\left(e_{j-1}-0\right)+\phi^{\prime}\left(e_{j-1}-0\right)\left(x_{j-1}-e_{j}\right)+(1 / 2) \phi^{\prime \prime}\left(e_{j-1}-0\right)\left(x_{j-1}-e_{j}\right)^{2}+\ldots
\end{aligned}
$$

Using the expressions (20) with neglected terms of order higher 2 gives

$$
\phi\left(x_{j+1}\right)-2 \phi\left(x_{j}\right)+\phi\left(x_{j-1}\right)=\phi^{\prime \prime}\left(x_{j}\right) h^{2}+\phi^{\prime \prime}\left(e_{j}\right) \alpha_{j}+\phi^{\prime \prime}\left(e_{j-1}\right) \alpha_{j-1},
$$

with

$$
\begin{gathered}
\alpha_{j}=\gamma_{j}\left(x_{j+1}-e_{j}\right)+h\left(\bar{x}_{j}-e_{j}\right), \quad \alpha_{j-1}=\gamma_{j-1}\left(e_{j-1}-x_{j-1}\right)+h\left(e_{j-1}-\bar{x}_{j-1}\right), \\
\bar{x}_{j}=\left(x_{j+1}+x_{j}\right) / 2, \quad \bar{x}_{j-1}=\left(x_{j}+x_{j-1}\right) / 2 .
\end{gathered}
$$

Recalling the notations introduced for approximate curvature one gets finally

$$
\widehat{\phi}^{\prime \prime}\left(x_{j}\right)-\phi^{\prime \prime}\left(x_{j}\right)=\beta_{j} \phi^{\prime \prime}\left(x_{j}\right),
$$

where

$$
\beta_{j}=\frac{\widehat{\phi}^{\prime \prime}\left(x_{j}\right)}{\phi^{\prime \prime}\left(x_{j}\right)}-1=\frac{\phi^{\prime \prime}\left(e_{j}\right) \alpha_{j}+\phi^{\prime \prime}\left(e_{j-1}\right) \alpha_{j-1}}{\phi^{\prime \prime}\left(x_{j}\right) h^{2}} \simeq \frac{\phi^{\prime \prime}\left(e_{j}\right) \gamma_{j}+\phi^{\prime \prime}\left(e_{j-1}\right) \gamma_{j-1}}{2 \phi^{\prime \prime}\left(x_{j}\right) h}+O\left(h^{2}\right) \text {. }
$$

In case of no crack surrounding the mesh point $x_{j}$, one has got $\hat{\phi}^{\prime \prime}\left(x_{j}\right)-\phi^{\prime \prime}\left(x_{j}\right)=$ $O\left(h^{2}\right)$, that implies negligible difference between approximate and exact curvatures at an intact section, i.e.,

$$
\hat{\phi}_{0}^{\prime \prime}\left(x_{j}\right)-\phi_{0}^{\prime \prime}\left(x_{j}\right)=O\left(h^{2}\right) .
$$

On the other hand, if both the crack locations coincide with $x_{j}$, i.e., $e_{j-1}=e_{j}=x_{j}$, $\gamma_{j-1}=\gamma_{j}$, Eq. (22) gives

$$
\hat{\phi}^{\prime \prime}\left(x_{j}\right)-\phi^{\prime \prime}\left(x_{j}\right)=\gamma_{j} \phi^{\prime \prime}\left(x_{j}\right) / h .
$$

The latter equation shows that miscalculation of the Laplacian curvature at a crack position depends on the crack magnitude, value of curvature at the crack and resolution step. Namely, the miscalculation gets to be increasing with reduction of the step $h$ and grow with the crack magnitude $\gamma_{j}$. Also, crack appeared at the node of curvature (where curvature vanishes) makes no effect on the mode shape, curvature including the approximate one.

In general, Eqs. (22), (24) allow one to obtain

$$
\Delta \widehat{\phi}^{\prime \prime}\left(x_{j}\right)=\widehat{\phi}^{\prime \prime}\left(x_{j}\right)-\widehat{\phi}_{0}^{\prime \prime}\left(x_{j}\right)=\Delta \phi^{\prime \prime}\left(x_{j}\right)+\beta_{j} \phi^{\prime \prime}\left(x_{j}\right),
$$


where

$$
\Delta \phi^{\prime \prime}\left(x_{j}\right)=\phi^{\prime \prime}\left(x_{j}\right)-\phi_{0}^{\prime \prime}\left(x_{j}\right) .
$$

It can be seen from Eq. (26) that the miscalculation of the approximate curvature increases its sensitivity to crack in comparison with exact curvature. For illustration of the fact, deviation of the Laplacian curvature due to multiple cracks is calculated by using expression (16) for three lowest modes of cantilever beam and results are demonstrated in Fig. 3.

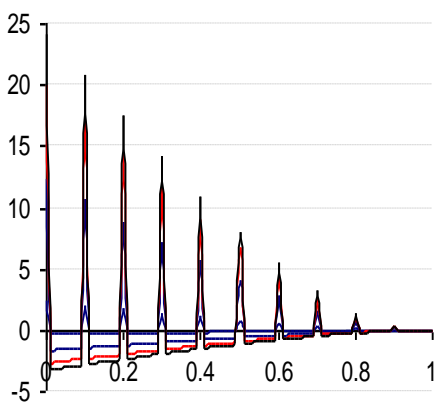

(a)

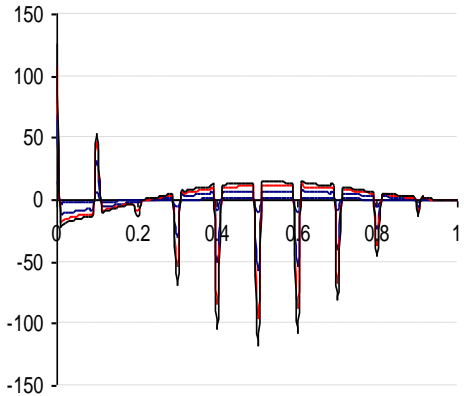

(b)

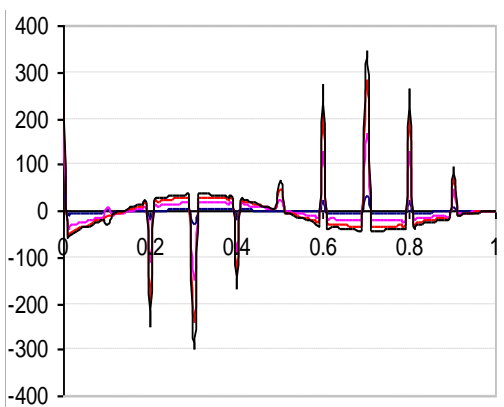

(c)

Fig. 3. Deviation of approximate curvature of first three modes due to 9 cracks at $0.1-0.9$ with equal depth $10 \%, 30 \%, 50 \%, 60 \%$

Graphs shown in Fig. 3 demonstrate strong sensitivity of approximate curvature to either magnitude or position of cracks that confirms theoretically once more the usefulness of the approximate curvature in crack localization for beam that was only numerically acknowledged in a number of previous studies.

\section{CONCLUDING REMARKS}

The main results of this study can be summarized as follow:

- An expression for exact mode shapes and mode shape curvatures have been obtained for multiple cracked beams that provides an efficient tool for analysis and identification of the beam structures.

- Using the obtained expression, it was shown that mode shape curvature is really more sensitive to cracks than the mode shape itself, however, the exact curvature sensitivity to crack is much less than that of approximate curvature calculated by the finite difference approximation.

- The paradox can be explained by the fact that sensitivity of the approximate curvature to crack is magnified by its miscalculation, that is also strongly depended upon crack magnitude and resolution step.

- Finally, the approximate Laplacian curvature would be a useful indicator for multiple-crack detection, if the base-line mode shape has been measured with sufficient accuracy. 
- The effect of noise in measurement of mode shape on the sensitivity of the approximate curvature to crack is not yet considered in the present paper, it would be a topic for further study of the author.

\section{ACKNOWLEDGEMENT}

The author is thankful to Vietnam Academy of Science and Technology for its support under grant of ID: NVCC03.02/20-20.

\section{REFERENCES}

[1] S. W. Doebling, C. R. Farrar, M. B. Prime, and D. W. Shevitz. Damage identification and health monitoring of structural and mechanical systems from changes in their vibration characteristics: a literature review. Technical report, No. LA-13070-MS, Los Alamos National Lab., NM (United States), (1996).

[2] S. W. Doebling, C. R. Farrar, and M. B. Prime. A summary review of vibration-based damage identification methods. Shock and Vibration Digest, 30, (2), (1998), pp. 91-105. https://doi.org/10.1177/058310249803000201.

[3] E. P. Carden and P. Fanning. Vibration based condition monitoring: a review. Structural Health Monitoring, 3, (4), (2004), pp. 355-377. https://doi.org/10.1177/1475921704047500.

[4] W. Fan and P. Qiao. Vibration-based damage identification methods: a review and comparative study. Structural Health Monitoring, 10, (1), (2011), pp. 83-111. https://doi.org/10.1177/1475921710365419.

[5] O.S. Salawu. Detection of structural damage through changes in frequency: a review. Engineering Structures, 19, (9), (1997), pp. 718-723. https://doi.org/10.1016/s0141-0296(96)001496.

[6] P. F. Rizos, N. Aspragathos, and A. D. Dimarogonas. Identification of crack location and magnitude in a cantilever beam from the vibration modes. Journal of Sound and Vibration, 138, (3), (1990), pp. 381-388. https://doi.org/10.1016/0022-460x(90)90593-o.

[7] J.-T. Kim, Y.-S. Ryu, H.-M. Cho, and N. Stubbs. Damage identification in beam-type structures: frequency-based method vs mode-shape-based method. Engineering Structures, 25, (1), (2003), pp. 57-67. https://doi.org/10.1016/s0141-0296(02)00118-9.

[8] K. R. P. Babu, B. R. Kumar, K. L. Narayana, and K. M. Rao. Multiple crack detection in beams from the differences in curvature mode shapes. ARPN Journal of Engineering and Applied Sciences, 10, (4), (2015).

[9] E. Sazonov and P. Klinkhachorn. Optimal spatial sampling interval for damage detection by curvature or strain energy mode shapes. Journal of Sound and Vibration, 285, (4-5), (2005), pp. 783-801. https://doi.org/10.1016/j.jsv.2004.08.021.

[10] M. Cao, M. Radzieński, W. Xu, and W. Ostachowicz. Identification of multiple damage in beams based on robust curvature mode shapes. Mechanical Systems and Signal Processing, 46, (2), (2014), pp. 468-480. https://doi.org/10.1016/j.ymssp.2014.01.004.

[11] D. Dessi and G. Camerlengo. Damage identification techniques via modal curvature analysis: overview and comparison. Mechanical Systems and Signal Processing, 52, (2015), pp. 181205. https://doi.org/10.1016/j.ymssp.2014.05.031.

[12] J. Ciambella and F. Vestroni. The use of modal curvatures for damage localization in beam-type structures. Journal of Sound and Vibration, 340, (2015), pp. 126-137. https://doi.org/10.1016/j.jsv.2014.11.037. 
[13] G. Raju and L. Ramesh. Crack detection in structural beams by using curvature mode shapes. IJIRST-International Journal for Innovative Research in Science E Technology, 3, (2), (2016), pp. 282-289.

[14] A. C. Altunışık, F. Y. Okur, S. Karaca, and V. Kahya. Vibration-based damage detection in beam structures with multiple cracks: modal curvature vs. modal flexibility methods. Nondestructive Testing and Evaluation, 34, (1), (2019), pp. 33-53. https://doi.org/10.1080/10589759.2018.1518445.

[15] A. K. Pandey, M. Biswas, and M. M. Samman. Damage detection from changes in curvature mode shapes. Journal of Sound and Vibration, 145, (2), (1991), pp. 321-332. https://doi.org/10.1016/0022-460x(91)90595-b.

[16] M. M. A. Wahab and G. De Roeck. Damage detection in bridges using modal curvatures: application to a real damage scenario. Journal of Sound and Vibration, 226, (2), (1999), pp. 217235. https://doi.org/10.1006/jsvi.1999.2295.

[17] C. P. Ratcliffe. Damage detection using a modified Laplacian operator on mode shape data. Journal of Sound and Vibration, 204, (3), (1997), pp. 505-517. https://doi.org/10.1006/jsvi.1997.0961.

[18] C. P. Ratcliffe. A frequency and curvature based experimental method for locating damage in structures. Journal of Vibration and Acoustics, 122, (3), (2000), pp. 324-329. https://doi.org/10.1115/1.1303121.

[19] M. Cao and P. Qiao. Novel Laplacian scheme and multiresolution modal curvatures for structural damage identification. Mechanical Systems and Signal Processing, 23, (4), (2009), pp. 12231242. https://doi.org/10.1016/j.ymssp.2008.10.001.

[20] M. Chandrashekhar and R. Ganguli. Structural damage detection using modal curvature and fuzzy logic. Structural Health Monitoring, 8, (4), (2009), pp. 267-282. https://doi.org/10.1177/1475921708102088.

[21] M. M. R. Taha, A. Noureldin, J. L. Lucero, and T. J. Baca. Wavelet transform for structural health monitoring: a compendium of uses and features. Structural Health Monitoring, 5, (3), (2006), pp. 267-295. https://doi.org/10.1177/1475921706067741.

[22] T. V. Lien and N. T. Duc. Crack identification in multiple cracked beams made of functionally graded material by using stationary wavelet transform of mode shapes. Vietnam Journal of Mechanics, 41, (2), (2019), pp. 105-126. https://doi.org/10.15625/0866-7136/12835.

[23] N. G. Jaiswal and D. W. Pande. Sensitizing the mode shapes of beam towards damage detection using curvature and wavelet transform. Int. J. Sci. Technol. Res., 4, (4), (2015), pp. 266-272.

[24] N. T. Khiem and H. T. Tran. A procedure for multiple crack identification in beam-like structures from natural vibration mode. Journal of Vibration and Control, 20, (9), (2014), pp. 14171427.

[25] T. G. Chondros, A. D. Dimarogonas, and J. Yao. A continuous cracked beam vibration theory. Journal of Sound and Vibration, 215, (1), (1998), pp. 17-34. https://doi.org/10.1006/jsvi.1998.1640. 